\title{
SEM/EDS Studies of Impurities in Natural Ice
}

\author{
D. Cullen, D. Iliescu and I. Baker
}

Thayer School of Engineering, Dartmouth College, Hanover, NH 03755, U.S.A.

The microstructural location of impurities in natural polycrystalline ice has been of interest for over a century. Recently, we have developed a technique to examine impurities in ice that involves controlled preferential sublimation of uncoated ice in a low-vacuum SEM. This leaves behind concentrated impurities at the triple junctions, within the grain boundaries (GBs) and in the grain interiors, which can then be identified using x-ray microanalysis.

The ice examined was from cores taken from GISP2, Greenland; Byrd Station, Antarctica; Vostok Station, Antarctica; Lower Baker Pond, Wentworth, NH and the Connecticut River, Hanover, NH.

For examination in the SEM, the surface of each section was shaved flat with a carefully-cleaned razor blade under a HEPA-filtered, laminar-flow hood. The section was then frozen onto a brass plate and mounted onto a cold stage. The cold stage was cooled using cold, flowing nitrogen gas that had passed through a liquid nitrogen-cooled heat exchanger. The temperature of the stage was monitored using a thermocouple mounted near the specimen. The specimens were held at158-188 K $\pm 5 \mathrm{~K}$ and examined at $10 \mathrm{kV}$ using a JEOL 5310LV SEM, equipped with a PGT IMIX EDS system utilizing a pure germanium, aluminum-coated polyimide thin-window detector. The EDS was used in a light element optimization mode that enables elements as light as boron to be detected. The EDS data are all for 100,000 total counts. Secondary electrons were used for imaging. Although ice is non-conducting, there is sufficient sublimation from the ice to produce enough ionized water molecules around the electron beam to neutralize charging of the specimen surface. Thus, the ice did not need to be coated. Prior to examination in the SEM, the ice specimens were allowed to sublimate at $253 \mathrm{~K}$ in small sealed containers for times from a few hours to two weeks. Sublimation was also performed in the SEM chamber at temperatures from 158-213 K.

All polar ice cores showed similar impurities, such as $\mathrm{Cl}, \mathrm{S}$ and less-commonly $\mathrm{Na}, \mathrm{Ca}$ and $\mathrm{Mg}$, throughout the material. In the GISP2 ice, filaments consisting chiefly of $\mathrm{NaCl}$ wereobserved in the GBs (FIG.1). These are thought to form by coalescence of the impurities that were located in the GB plane. In contrast, the Byrd ice contained occasional filaments of MgS in the GBs while the Vostok accretion ice contained magnesium sulfate crystals in the grain triple junctions. The grain interiors in both the lake and river ice also contained impurities. However, in river ice, most of the impurities present, which reflected the surrounding geology, were located in inclusions of $=20 \mu \mathrm{m}$ diameter in or in the immediate vicinity of the GBs. In contrast, the pond ice contained many unusually-shaped, but often facted, hexagonal-symmetry features from 200-1000 $\mu \mathrm{m}$ in diameter which were located both on or near the GBs and in the interior of the grains. These features appear to be small ice crystals that have nucleated on impurities and, initially, grew under quasi-equilibrium conditions. Later, non-equilibrium radial growth transformed such hexagonal crystals into hemispherical features. Sublimation of these latter features produced the caldera-like features, shown in FIG 2(a), which showed substantial concentrations of impurities (FIG. 2(b)).

This research was supported by U.S. National Science Foundation grant OPP-9980379 and Army Research Office grant DAAD 19-00-1-0444. 


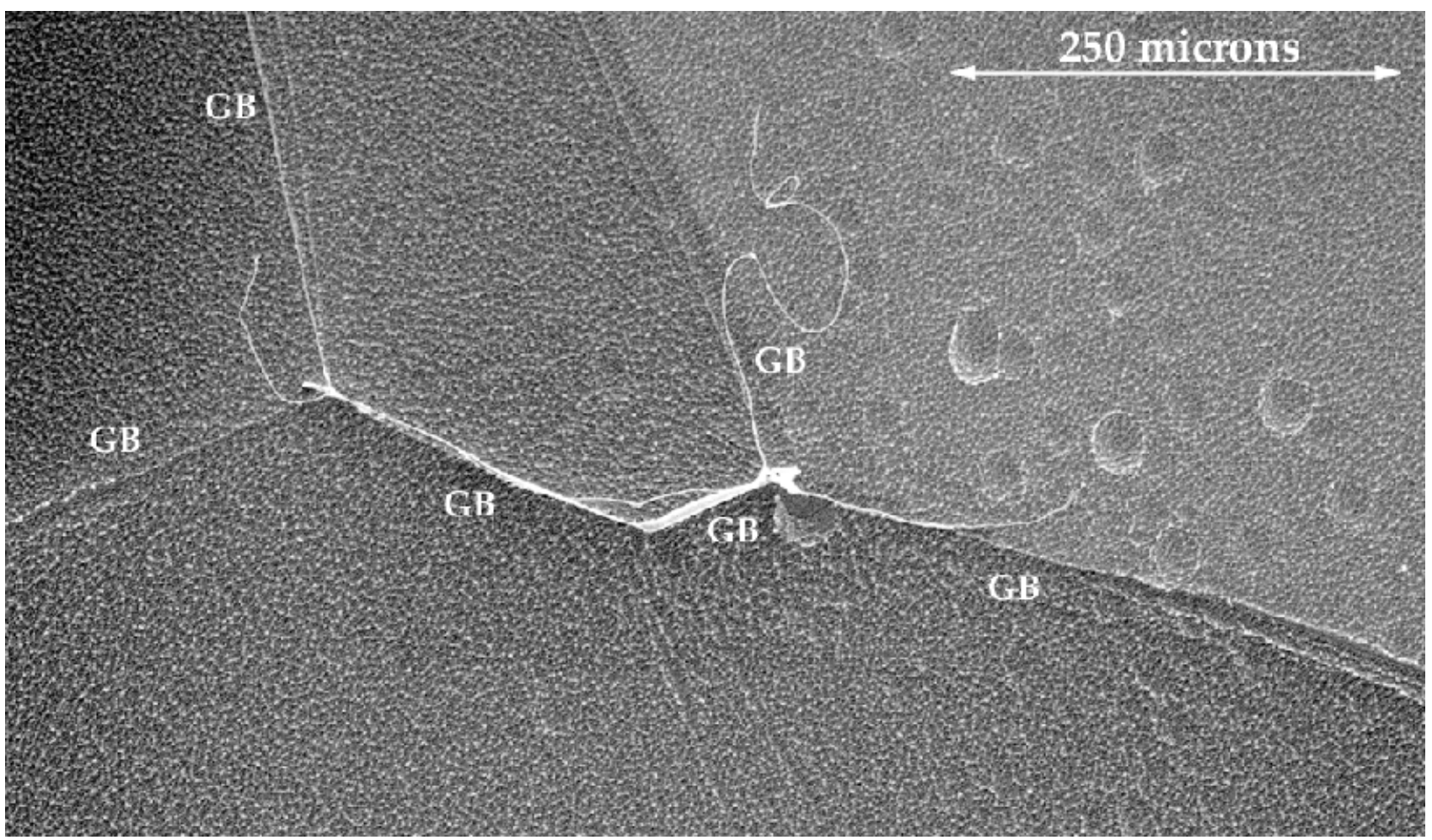

FIG.1. Ice from a depth of $214 \mathrm{~m}$ at GISP2 showing grain boundary filaments, where some of the filaments have peeled out of the grain boundary.

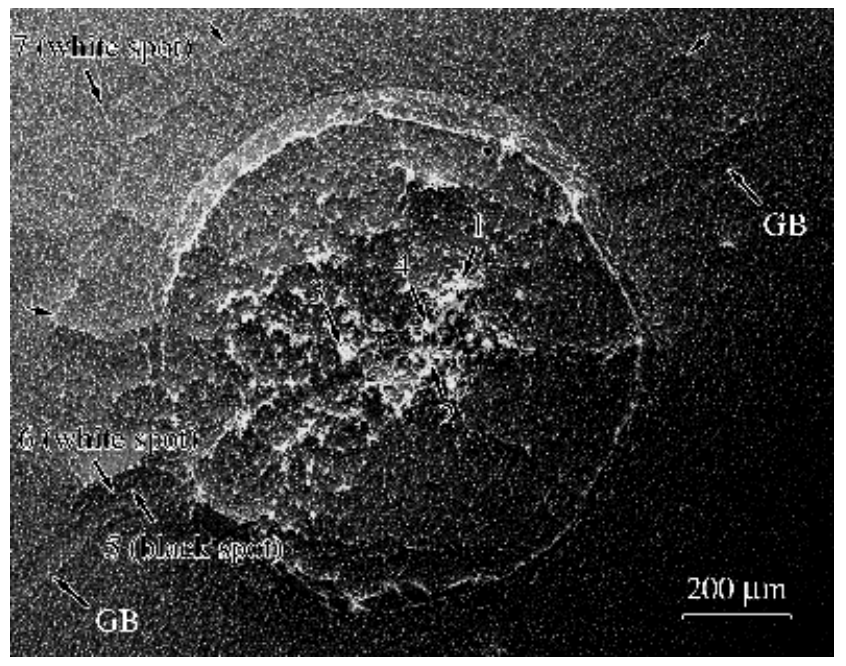

(a)

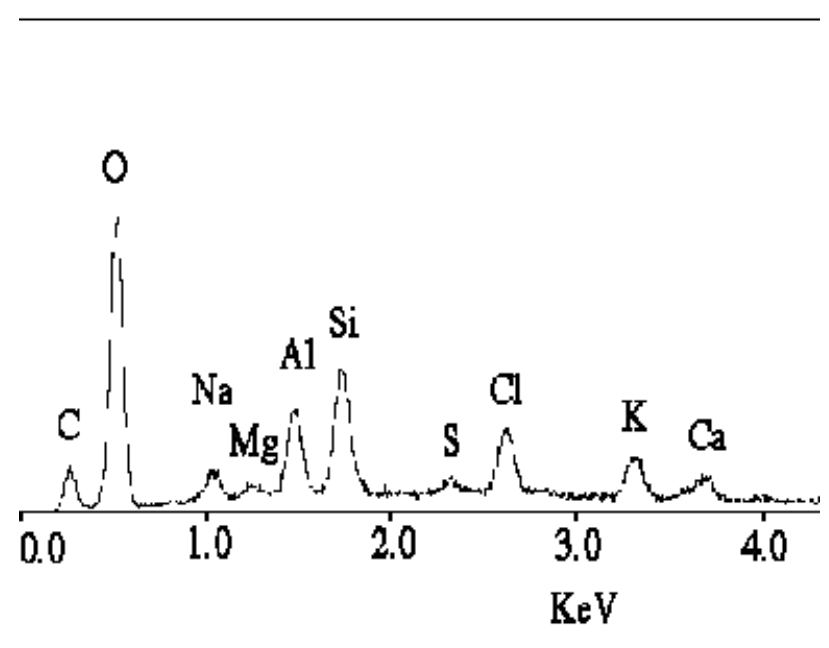

(b)

FIGURE 2. (a) Feature observed in a GB in pond ice after sublimation in the LVSEM; and (b) X-ray spectrum from point 2 in (a); Full scale $=1800$ counts. 